\title{
Biclausal vs. monoclausal focus constructions in Tilapa Otomi
}

\author{
Enrique L. Palancar \\ SeDyL, CNRS \\ Faits de Langues 51.2
}

\author{
Special Issue « Clefts and other related focus constructions » \\ Enrique L. Palancar \& Martine Vanhove (eds.)
}

This paper tackles issues that involve distinguishing clefts from other monoclausal focus constructions when describing the syntax of lesser-known languages. I concentrate on Tilapa Otomi, which is the most endangered and the most morphologically conservative language of Otomi family; an Amerindian language family from Mexico that belongs to the OtoManguean phylum. In the paper, I propose that Tilapa Otomi has (at least) two specialized focus constructions: one that is a biclausal, thus a cleft, and another that is monoclausal, but which shares structure with clefts, to the extent that superficially could be taken to be an instance of a cleft with a zero copula.

\section{Introduction ${ }^{1}$}

Following Drubig and Schaffar (2001: 1079), I take a focus construction to be a construction that "(...) denotes a type of sentence that serves to promote a specified constituent, its focus, to a position of particular prominence by setting it off from the rest of the sentence in one way or another." Focus constructions come in a variety of ways, but one fundamental dimension to typologize them is whether they represent biclausal or monoclausal structures. The type of biclausal focus constructions par excellence are clefts ${ }^{2}$. They are biclausal because they consist of two clauses: a matrix clause (i.e., the specificational copular construction with a copular predicate, a subject phrase and a complement phrase) and a subordinate clause, typically in the form of a headless relative clause. English has a variety of cleft constructions, among them the types in (1) are well-known. The cleft construction in (1a) is an instance of the well-known type called it-cleft (Patten, 2012), while the clefts in (1b) are called 'pseudo-clefts'. ${ }^{3}$ In clefts, we have three main elements, the copular predicate, the focus phrase (henceforth FP) and the subordinate clause the background information against which the focus element is identified. In other words, the background has a variable

\footnotetext{
${ }^{1}$ Acknowledgements: I want to heartily thank the three anonymous reviewers of this article for their time and for their invaluable comments and suggestions. I am also grateful to the discussion with the participants of the 2018 workshop "Clefts and related focus constructions" at Paris-Villejuif as part of the LABEX-EFL project "The typology and corpus annotation of information structure and grammatical relations". All errors and deficiencies remain my only responsibility.

${ }^{2}$ While there have been other definitions of clefts in the literature (for example Jespersen, 1949: 147f.), I follow here the one in Lambrecht's (2001: 467), where it is stated that "A cleft construction is a complex sentence structure consisting of a matrix clause headed by a copula and a relative or relative-like clause whose relativized argument is co-indexed with the predicative argument of the copula. Taken together, the matrix and the relative express a logically simple proposition, which can also be expressed in the form of a single clause without a change in truth conditions."

${ }^{3}$ As argued by Lambrecht (2001), pseudo-clefts are cleft constructions because they can be paraphrased in one simple clause. Patten (2012:68) rightly points out that the label 'pseudo' in pseudo-clefts (as opposed to it-clefts, which would be considered the 'genuine' clefts under that view) originates in the fact that the copular structure in (1b) also allows for other instances that look like clefts but aren't, because they cannot be paraphrased into a simple clause (e.g. what I like about it is that it's so sweet).
} 
to be identified (i.e., there is somebody who saw me, but the identity of that somebody is yet to be established). The element that is presented as the value for that variable is the focus (i.e., the speaker asserts that the identity of that somebody is Mary). ${ }^{4} \mathrm{I}$ refer to this type of clause as the 'clefted clause' (henceforth CC). In all examples, I mark the FP with simple brackets and the $\mathrm{CC}$ with curly ones.
a. It was $[\mathrm{MARY}]_{\mathrm{FP}}\{\text { who saw me }\}_{\mathrm{CC}}$
It-cleft
b. $[\text { MARY }]_{\mathrm{FP}}$ was $\{\text { who saw me }\}_{\mathrm{CC}}$
Inversed pseudo-cleft
c. $\{\text { who saw me }\}_{\mathrm{CC}}$ was $[\mathrm{MARY}]_{\mathrm{FP}}$
(Direct) pseudo-cleft

Biclausal focus constructions contrast with monoclausal ones, like (2), where the FP is only signalled by stress (i.e., only by means of prosody).

\section{(2) $[\text { MARY }]_{\mathrm{FP}}$ saw me}

But while the examples in (1) are instances of specialized focus constructions in the grammar of the English language, it could be argued that (2) is not, at least not from a syntactic and morphosyntactic point of view, because the focus is just marked prosodically. In this paper, I show that Tilapa Otomi has (at least) two specialized focus constructions. One is the biclausal focus construction in (3), which is a cleft, ${ }^{5}$ the other is the monoclausal focus construction in (4). The latter involves a fronted FP and a string encoding the background that contains the focus-extracted pronoun $k o$. Most examples in this paper come from natural texts collected from my own documentation activities in the language (such examples are indicated with the abbreviation ' $\mathrm{Txt}$ ') ${ }^{6}$

$$
\begin{array}{llll}
\text { ken }=\text { ts'e } & {[n i} & \text { Sergio }]_{\mathrm{FP}} & \left\{\mathrm{be}={ }^{\prime} \mathrm{e} h=\mathrm{a}={ }^{\prime} \mathrm{mba}\right\}_{\mathrm{CC}} \\
\text { COP.AS=just } & \text { DEM.SG } & \text { S. } & {[3] \mathrm{CPL}=\mathrm{come} . \mathrm{AS}=\mathrm{CL}=\text { then }}
\end{array}
$$

'It was just Sergio who came then.' (Txt)

(Lit. 'Sergio was just who came then.')

$$
\begin{aligned}
& {[\tilde{n} \ddot{u}=a]_{\mathrm{FP}} \quad \text { ko } \quad \mathrm{ti}={ }^{\mathrm{h}} \text { peteti }} \\
& {\text { PRTCL }=3 \mathrm{SG}_{\text {PRO }}} \quad \text { HUM.FOC } \quad[3] \mathrm{CPL} . I R R=\text { make.tortillas } \\
& \text { 'SHE makes tortillas.' (Txt) }
\end{aligned}
$$

In the paper, I argue that the construction in (4) is a monoclausal construction against the analysis in Palancar (2018a), who proposes that it could be treated as a cleft with a zero copula. Such monoclausal construction is used as the default encoding when a human being, encoded by a pronominal (i.e., an established discourse topic), is placed in focus, just like in (4). This construction is introduced in the last section (\$4) before conclusions. I further show in $\S 3$, that the string be 'ëha'mba in the cleft in (3) is a headless relative clause serving as the $\mathrm{CC}$, even though it does not superficially look like a subordinate clause (i.e., it is not

${ }^{4}$ I follow Lambrecht's (1994: 207) take on focus as a relational category, where focus is defined as "that portion of a proposition which cannot be taken for granted at the time of the speech. It is the unpredictable or pragmatically non-recoverable element in an utterance. The focus is what makes an utterance into an assertion." ${ }^{5}$ As I argue in \$2.4, Tilapa Otomi is a verb initial language, so the copula in the cleft in (3) occurs in the natural syntactic position of a predicate. This means, that despite its resemblance to the English example in (1a), the clefts of Tilapa Otomi are not it-clefts, but pseudo-clefts. However, in order to render them naturally as focus constructions in English, I have translated Tilapa Otomi clefts with it-clefts in English, because it-clefts feel like the closest functional equivalent to the Tilapa Otomi construction. For clarification, in some of the examples I have also included a literal translation with a pseudo-cleft in English.

${ }^{6}$ Orthography: Deviations from the IPA. Consonants: C' $/ C^{?} /$ (ejective); ${ }^{h} C$ (pre-aspirated); $/ \mathrm{R} / ; \tilde{n} / \mathrm{n} / ;$ ch $/ \mathrm{tf} / ; t \dot{r}$

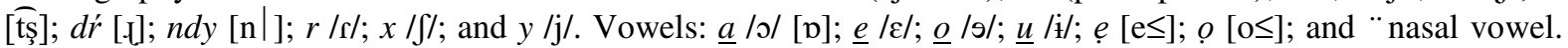
High tone is represented by an acute accent only in inflectional formatives. 
introduced by a relative pronoun or a complementizer). In contrast, the element $k o$ in the monoclausal construction in (4), which could look like a relative pronoun introducing a CC is neither a relative pronoun nor does it occur in the typical high syntactic position of relative pronouns. This is shown in $\$ 4.2$. To show all this, I first introduce some basic facts about Otomi grammar which are important to understand the syntax of focus constructions. I focus on clefts in $\S 3$. As mentioned, the focus construction I introduce in this paper is treated in $\S 4$. Conclusions appear in $\S 5$.

\section{Basics about Tilapa Otomi grammar in relation to clefts}

Otomi is a small language family from Mexico that is classified as part of the Oto-Manguean stock. It consists of at least six different languages; three of them are large dialectal continua. The language I study in this paper is Tilapa Otomi, which is the most conservative language in the family from a morphological point of view. As proposed in Palancar (2018a), much in the characterization of the syntax of clefts in Tilapa Otomi can be transposable to the syntax of other Otomi languages, but there are substantial differences which still need to be addressed more comprehensively, especially in the light of the existence of other types of headless relative clauses, as proposed in (Hernández-Green, Forthcoming).

There are a few things that one needs to know about Otomi grammar in order to understand the syntax of clefts and other focus structures in Tilapa Otomi. I enumerate them here and elaborate on each one in the following subsections: a) inflectional properties of verbs with regard to the copula; b) pronominal enclitics; c) the syntax of the preverbal zone; and d) the basic word order and the particle $\tilde{n} \ddot{u}$.

\subsection{Verbal inflection and the copula}

Verbs in Tilapa Otomi inflect for tense/aspect/mood (TAM) values, associated motion and adverbial focalization by means of inflectional markers that always occur before the verbal stem. The markers in question may be phonologically hosted on the stem, like in (5a), or on preceding elements, like the negation adverb in (5b). I refer to such markers as inflectional formatives' and I treat them as clitics when they are monosyllabic.

$$
\begin{aligned}
& \text { a. 'ne gú }=\text { ndoya? } \\
& \text { and 2.CPL=notify[3OBJ] } \\
& \text { 'And did you notify her?' (Txt) } \\
& \text { b. hin = gú } \text { nde gi }=\text { ' } \underline{u n y}=\mathrm{a} \\
& \mathrm{NEG}=2 . \mathrm{CPL} \text { want 2.CPL.IRR=give.to.3.AS[3OBJ]=CL } \\
& \text { 'You didn't want to give it to him.' (Txt) }
\end{aligned}
$$

Note that inflectional formatives also encode person of the subject cumulatively with TAM, like the formative $g \underline{u}$ in (5) which encodes 2 nd person along with completive (of the realis mood). This happens in transitive verbs and active intransitive verbs alike. Table 1 shows the forms of three basic (and discourse frequent) TAM subparadigms of the transitive verb nde 'want'. 


\begin{tabular}{|c|c|c|c|}
\hline & \multicolumn{2}{|c|}{ 'want' } \\
\hline & & Realis & Irrealis \\
\hline \multirow[t]{3}{*}{ INCPL } & & truá nde & gra $n d e$ \\
\hline & $2^{\text {nd }}$ & grá nde & gra nde \\
\hline & $3^{\text {rd }}$ & ra $n d e$ & tŕa nde \\
\hline \multirow[t]{3}{*}{ HAB } & $1^{\mathrm{st}}$ & tŕú $n d e$ & gru $n d e$ \\
\hline & $2^{\text {nd }}$ & grú $n d e$ & gru \\
\hline & $3^{\text {rd }}$ & ru $n d e$ & tŕu $\underline{\underline{u}}$ nde \\
\hline \multirow[t]{3}{*}{ CPL } & $1^{\mathrm{st}}$ & tú $n d e$ & gu $n d e$ \\
\hline & $2^{\text {nd }}$ & gú $n d e$ & gi nde \\
\hline & $3^{\text {rd }}$ & bi nde & ti nde \\
\hline
\end{tabular}

Table 1. Three TAM subparadigms of $n d e$ 'want' in Tilapa Otomi

In contrast, inactive intransitive verbs inflect for person by means of person suffixes, like for example in (6a) ${ }^{7}$. The same suffixes are used to encode object of transitive verbs, like in (7a). A bare stem realizes 3 rd person, as in $(6 b)$ or $(7 b){ }^{8}$

(6)
a. $\quad$ bi $=$ hwötsi-gi
$\mathrm{CPL}=$ tremble.AS- $1 \mathrm{~S}_{\mathrm{o}}$
'Like I trembled.' (Txt)

(7)

a. bi =wïn-gi

[3]CPL=feed.AS-1OBJ

S/he/they fed me.' (Txt) b. bi = hwöts'i

$\mathrm{CPL}=$ tremble$\left[3 \mathrm{~s}_{0}\right]$

'S/he/they trembled.'

b. bi = wïni

[3]CPL=feed[3OBJ]

'S/he/they fed

him/her/them.'

While the copula is a predicate, it is not a verb in as much as it does not have the same inflectional properties that verbs have. For example, it does not select the same inflectional formatives that verbs do. The copula has, however, access to a mood distinction. This can be seen by the fact that the irrealis is marked by the inflectional formative $\underline{t} \underline{u}$, like in (8); the realis is unmarked.

$$
\begin{array}{llll}
\text { mö }=\underline{t u} & \text { kẹh }=\mathrm{a} & \text { di } & \text { tyy } \\
\text { although=IRR } & \text { COP.AS[3]=CL } & \text { 2.POSS } & \text { son } \\
\text { 'Although it may be your son.' (Txt) } &
\end{array}
$$

The copula is also an inactive intransitive predicate, as shown in (9). But just like any other non-verbal predicate, it cannot receive person suffixes, so person is encoded by pronominal enclitics (see next section).

$$
\begin{array}{ll}
\text { ken }=\text { ga } & \text { ma! } \\
\text { COP=1[SG] } & \text { Mother } \\
\text { 'It's me, mother.' (Txt) }
\end{array}
$$

\subsection{Pronominal enclitics}

We have seen in (9) that the copula receives the pronominal enclitic ga for 1st person. Pronominal enclitics cross-reference the person of the subject (much less commonly so, the

\footnotetext{
${ }^{7}$ Basic (non-derived) inactive verbs constitute a small class depicting various types of physical experiences over which the experiencer has no control. On the other hand, the passive forms of all transitive verbs are derived inactive verbs.

${ }^{8}$ In the examples, I only gloss reference to a 3rd person object (or subject of an inactive intransitive) when there is no overt DP in the clause.
} 
object). ${ }^{9}$ When they occur associated to the verb, they commonly encode notions of contrast, like in (10).

$$
\begin{aligned}
& \text { pues } g \underline{u}=x \underline{x}=\mathrm{xa}, \quad \text { porke }=\text { rá } \quad \text { 'wahki }=\text { thọ }=\text { gwa } \\
& \text { so 1.CPL.IRR=lift.AS[3OBJ] }=1[\mathrm{SG}]_{\mathrm{PRO}} \text { because }=\mathrm{INCPL} . \mathrm{ST} \quad \text { lie.in.the.open }\left[3 \mathrm{~s}_{\mathrm{O}}\right]=\mathrm{DEL}=\text { here } \\
& \text { 'Well, I'm going to put it (the fence) up myself, because it (the courtyard) is lying all } \\
& \text { in the open here.' (Txt) }
\end{aligned}
$$

In the clefts of Tilapa Otomi, the copula often hosts a pronominal enclitic to index the person of the FP, which is its subject. This is shown in (11). In $\$ 3.2$, I further show that such enclitics are also used in clefts to cross-reference the FP from the right-edge of the whole construction.

$$
\begin{aligned}
& \mathrm{keh}=\mathrm{a}[=\mathrm{ni}]_{\mathrm{FP}} \quad\{\mathrm{ti}=\mathrm{khah}-\mathrm{k} \underline{\mathrm{u}}=\mathrm{mal}\}_{\mathrm{CC}} \\
& \text { COP.AS=CL=DEM.SG} \quad[3] \mathrm{CPL} . \mathrm{IRR}=\mathrm{do} . \mathrm{DTR}-1[\mathrm{SG}] \mathrm{DAT}=\mathrm{bad} \\
& \text { 'That's what (commonly) upsets my stomach.' (Txt) } \\
& \text { (Lit. 'That's what does me bad.') }
\end{aligned}
$$

The paradigm of pronominal enclitics appears in Table 2. There are specific forms for 3rd person, but like in (11), deictics are often used pronominally too.

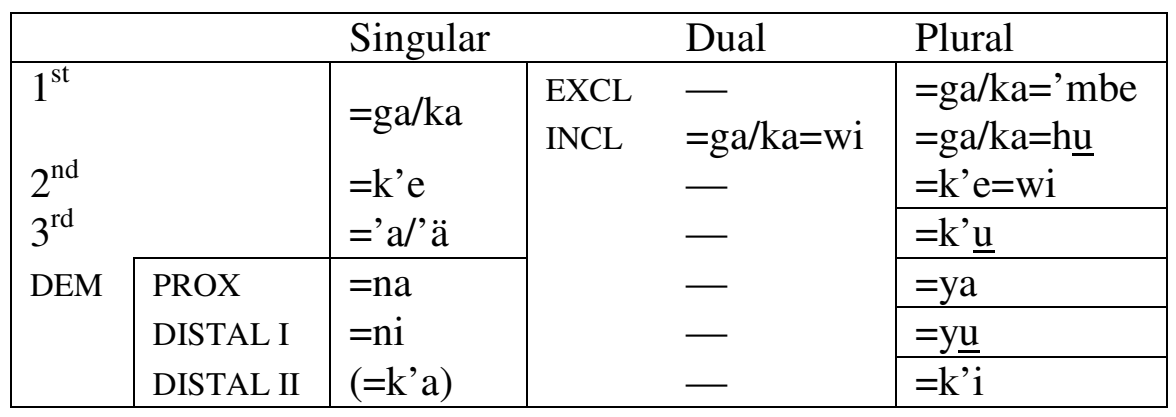

Table 2. Pronominal enclitics in Tilapa Otomi

\subsection{The preverbal zone}

In $§ 1$, I illustrated the monoclausal focus construction with example (4) and I commented on the fact that it involves the element ko, which I glossed as 'human focus'. To understand what the syntactic position of this element is in focus constructions, it is important to know the internal syntax of predicates in Otomi, because they may (and often) include a set of elements that occur at fixed positions preceding the inflectional formatives. Such elements include negation, adverbials and indefinite pronouns. I refer to the syntactic space where such elements occur as the "pre-V(erbal)" zone. Examples in (12) illustrate the use of the manner adverbial $k h \underline{a n}=$ (always a bound form) associated to a verb and to the copula, respectively. Example (12b) illustrates a cleft with a covert FP.

$$
\begin{array}{lll}
\text { a. 'ne } & \text { khan =dá } & \text { 'ё='mbe } \\
\text { and } & \text { MANN/REASON=1.CPL.ADV } & \text { come=PL.EXCL }
\end{array}
$$

\footnotetext{
${ }^{9}$ Pronominal enclitics are different from the person suffixes in (6-7) in various respects; three of them are important: (i) person suffixes are toneless, while pronominal enclitics bear lexical tone; (ii) a verbal stem bearing a person suffix can be prosodically bound to the first free word of a following phrase in a process that we can call 'compaction', like in example (16b) below. In contrast, a verbal stem hosting a pronominal enclitic never undergoes compaction together with the enclitic; on the contrary, the stem appears compacted in the same way it would when binding to a following free word; and (iii) pronominal enclitics host on different word classes, person suffixes are categorically dependent on the verb.
} 


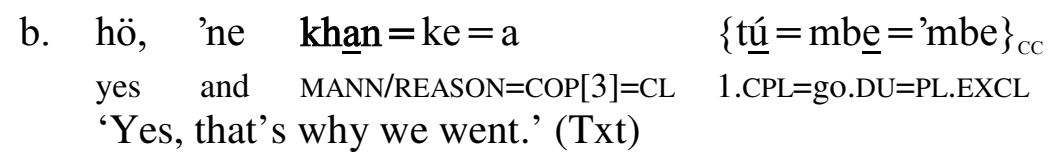

The marking of negation occurs towards the left-edge of this pre- $\mathrm{V}$ zone (i.e., any other adverbial element that may precede negation occurs in a syntactically independent (fronted) adverbial phrase). ${ }^{10}$ Examples of the negative marker are given in (13a) and (13b). Example (13b) has the indefinite pronoun te 'something'.

$$
\begin{array}{ll}
\text { a. hín= dŕú } \quad \text { htsi }=\text { ga } \\
\text { NEG=1.HAB ingest=1[SG]EMPH } \\
\text { 'I don't drink.' (txt) } \\
\text { b. hín=te } \quad \text { trú }={ }^{\text {h }} \text { tsi }=\mathrm{a} \\
\text { NEG=SOMETHING } \quad \text { 1.HAB=ingest=CL } \\
\text { 'I don't eat anything.' (txt) }
\end{array}
$$

\subsection{Basic word order and the particle $\tilde{n} \ddot{u}$}

Tilapa Otomi is a language with verb initial constituent order. This can be seen in (14), which instantiates the neutral VOS order of the language. Note that the alternative reading in (b) from a VSO interpretation is not possible. ${ }^{11}$ Verb initial configuration has been described as a Mesoamerican trait (Campbell et at. 1986), and it is found in the vast majority of OtoManguean languages. ${ }^{12}$
$\mathrm{bw} \underline{\mathrm{u}}={ }^{\mathrm{h}} \mathrm{tsi}$
$[\mathrm{a}$
nana $]_{\text {овJ }}\left[\begin{array}{ll}\mathrm{mu} & \mathrm{h} \\ \mathrm{ta}\end{array}\right]_{\mathrm{SBJ}}$
[3]CPL.VEN>EXLOC=take.animate DEF.SG woman $1 \overbrace{}^{\lambda}$ POSS father
a. 'My dad went to fetch the woman.' (Txt)
b. *'The woman went to fetch my dad.'

In clefts, instances where the copula occurs in initial position like in (15) should be taken to represent the natural word-order of the language (i.e., they are not cases of $i t$-clefts).

$$
\begin{array}{ll}
\mathrm{kẹh}=\mathrm{a}\left[={ }^{\prime} \mathrm{a}\right]_{\mathrm{FP}} & \left\{\text { trú }={ }^{\mathrm{h}} \mathrm{pe}={ }^{\mathrm{e}}=\mathrm{mbe}^{\mathrm{C}}=\mathrm{a}\right\}_{\mathrm{CC}} \\
\mathrm{COP}=\mathrm{CL}=3 \mathrm{SG} & \text { 1.HAB=work.on. something=PL.EXCL.CL }
\end{array}
$$

'It's what we do.' (Txt)

Subject phrases (by way of DPs or pronominal phrases) can also be found to the left of the predicate, where they often function as contrastive topics, like in (16) (fronted objects occur much more rarely).
a. 'ne $\left[\begin{array}{ll}a & \text { kha'ni }\end{array}\right]_{\text {SBJ }} \quad b i=$ 'yehpi-gi
and DEF.SG person [3]CPL=SS/throw-1OBJ
'And the man threw me away.' (Txt)
b. $\quad$ mientras $=[\mathrm{ga}]_{\mathrm{SBJ}} \quad \mathrm{g} \underline{\mathrm{u}}={ }^{\prime} \underline{\mathrm{ot}}{ }^{\prime} \underline{\mathrm{u}} \approx \mathrm{ni} \quad$ 'i
while $=1[\mathrm{SG}]_{\text {PRO }} \quad$ 1.CPL.IRR $=$ make.AS $\approx$ DEM.SG food
'While I will make the food' (Txt)

\footnotetext{
${ }^{10}$ There appear to be cases where the quantifying adverb mas 'more' occurs before the negation to modify it, but such cases do not represent a different syntactic position in the pre- $\mathrm{V}$ zone.

${ }^{11}$ Other Otomi languages have other basic word-orders; for example, the closest neighbouring living language, Acazulco Otomi has VSO (Hernández-Green, 2015).

${ }^{12} \mathrm{~A}$ notable exception to this is Chichimec (Oto-Pamean) which is verb final, as reported in the materials in Angulo (1933), and more recently also in Lizarraga Navarro (2018). Similarly, Campbell (in press) reports a verb final example of a complementation construction involving a desiderative matrix verb, which is also verb final.
} 
However, when such fronted phrases are used, more often than not they are introduced by the particle $\tilde{n} \ddot{u}$, like in (17).

$$
\begin{aligned}
& \text { a. kha }\left[\tilde{n} \ddot{u}=k^{\prime} e=a\right] \quad \text { hin }=\text { gú } \quad \text { syön-gi }=a \\
& \text { and } \quad \mathrm{PRTCL}=2[\mathrm{SG}]=\mathrm{CL} \quad \mathrm{NEG}=2 . \mathrm{CPL} \quad \mathrm{SS} / \text { look.for }-1 \mathrm{OBJ}=\mathrm{CL} \\
& \text { 'And YOU didn't look for me.' (Txt) } \\
& \text { b. 'ne }[\tilde{n} \ddot{u} \text { i } x \text { angot'ö }] \quad g i=\text { tsendy }=a \\
& \text { and PRTCL PL sanacoche 2.CPL.IRR }=\text { smash. } \mathrm{AS}=\mathrm{CL} \\
& \text { 'And you smash the SANACOCHE (a root used as soap).' } \\
& \text { (Txt) }
\end{aligned}
$$

In Tilapa Otomi, phrases introduced by ñü cannot occur in a position internal to the VP. This means that pronominal phrases (i.e. based on $\tilde{n} \ddot{u}$ ) always occur fronted in the clause. This is illustrated by the ungrammaticality of the examples in (18).

$$
\begin{aligned}
& \text { a. *kha hin }=\text { gú } \quad \text { syön-gi }=\mathrm{a} \quad\left[\tilde{\mathrm{n}} \ddot{\mathrm{u}}=\mathrm{k}{ }^{\prime} \mathrm{e}=\mathrm{a}\right] \\
& \text { and } \quad \mathrm{NEG}=2 . \mathrm{CPL} \quad \mathrm{SS} / \text { look.for }-1 \mathrm{OBJ}=\mathrm{CL} \quad \mathrm{PRTCL}=2[\mathrm{SG}]=\mathrm{CL} \\
& \text { Intended reading: 'And YOU didn't look for me.' } \\
& \text { b. *'ne gi=tsendy }=\mathrm{a} \quad \text { [ñü i } \quad \text { xangot'ö] } \\
& \text { and 2.CPL.IRR=smash.AS=CL PRTCL PL Sanacoche } \\
& \text { Intended reading: 'And you smash the SANACOCHE.' }
\end{aligned}
$$

The pin-pointing of the precise pragmatic-syntactic function of the particle $\tilde{n} \ddot{u}$ is challenging, and it deserves an independent study of its own, especially from an Otomi pan-dialectal perspective. When it is associated to a DP, in Tilapa Otomi it serves as a presentational marker that (re)introduces a (definite) DP as topic. A clear example is (19), which is an instance of an external topic, with a pause after the topic phrase separating it from the rest of the utterance ${ }^{13}$. There is also a pronominal enclitic on the verb that cross-references the extracted object. ${ }^{14}$

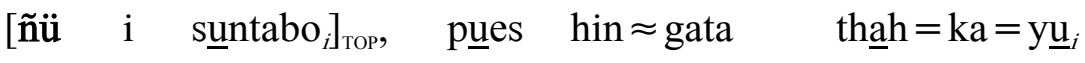

$$
\begin{aligned}
& \text { PRTLC PL cent well NEG } \approx 1 \text {.ADLAT.IRR meet/find.AS }=1[\mathrm{SG}]_{\text {PRO }}=\text { DEM.PLPRO } \\
& \text { 'The cents, well so I'm not going to find them.' (Txt) }
\end{aligned}
$$

The particle $\tilde{n} \ddot{u}$ serves as a base to form pronominal phrases. Example (16b) above shows that pronominal enclitics can be hosted on adverbs or conjunctions at the left-edge of the sentence, but this only happens when the pronoun is topical; it never happens when it is in focus. Although fronted pronominal phrases based on $\tilde{n} \ddot{u}$ can also be topical, they are most commonly used focally. But when this happens, the pronominal phrase also forms part of a focus construction, may it be of the cleft type in (20) or of the monoclausal focus construction in (4), repeated here as (21). This suggests that the pragmatic force of focus of a pronoun is not conveyed by the particle $\tilde{n} \ddot{u}$ per se, but that it obtains instead through a combination of circumstances: the pragmatic context; the privileged syntactic position to the left of the predicate; and the specialized focus construction.

$$
\begin{aligned}
& \text { pero }[\tilde{n} \ddot{u}=\mathrm{a}=\mathrm{ya}]_{\mathrm{FP}} \quad \mathrm{ke}=\mathrm{a} \quad\{\text { giti } \quad \text { k'oty }=\mathrm{a}\}_{\mathrm{CC}}=\text { ya } \\
& \text { but } \quad \mathrm{PRTCL}=\mathrm{CL}=\mathrm{DEM} . \mathrm{PL}_{\mathrm{PRO}} \quad \mathrm{COP}=\mathrm{CL}[3] \quad \text { 2.CPL.IRR. } . \mathrm{ADV} \quad \text { clean. } . \mathrm{AS}=\mathrm{CL}=\mathrm{DEM} . \mathrm{PL}_{\mathrm{PRO}} \\
& \text { 'But it's with that you're going to clean it.' (Txt) } \\
& \text { (Lit. 'But THOSE (the ashes) are what you're going to wash it with.' }
\end{aligned}
$$

\footnotetext{
${ }^{13}$ The discourse particle pues 'well/so' (Spanish pues) in (19) also always occurs in initial position.

${ }^{14}$ Such enclitics are optional, but they are nonetheless common in this context. The use of $\tilde{n} \ddot{u}$ with a topicalized DP is facultative when the DP functions as subject, except when the phrase includes a possessed noun, but it is obligatory when it functions as object.
} 


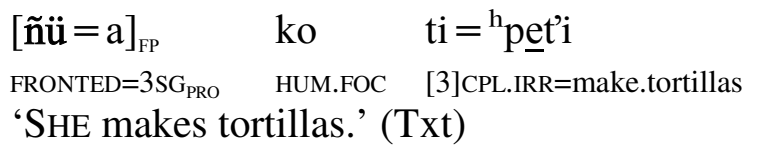

In this section, we have seen a set of grammatical properties of Otomi clauses which set the larger context to understand the structure of focus constructions, namely that the language is verb initial and that predicates are preceded by a set of syntactic positions where certain adverbial and pronominal elements occur. We have also seen that the copula in a cleft is a non-verbal inactive predicate, that person can be encoded by pronominal enclitics and that fronted constituents are often introduced by the presentational particle $\tilde{n} \ddot{u}$. In the next section, I concentrate on other structural characteristics of clefts in Tilapa Otomi. First, in \$3.1 I propose that the syntactic string that encodes the background in a cleft is a relative clause. Then I introduce two properties which are particularly interesting of the cleft construction in Otomi: the syntactic cross-referencing of the FP by pronominal enclitics (§3.2) and the use of fronted FP (§3.3).

\section{Clefts in more detail}

\subsection{Relative clauses and the $\mathrm{CC}$ in the clefts}

In this section, I show that the string be 'ëha'mba 'he came then' in a cleft like (3) above, repeated here as (22), is a headless relative clause.

$$
\begin{array}{llll}
\text { ken }=\text { ts'e } & {[\text { ni }} & \text { Sergio }]_{\mathrm{FP}} & \left\{\mathrm{be}={ }^{\prime e ̈ h}=\mathrm{a}={ }^{\prime} \mathrm{mba}\right\}_{\mathrm{CC}} \\
\text { COP.AS=just } & \text { DEM.SG } & \text { S. } & {[3] \mathrm{CPL}=\text { come. } \mathrm{AS}=\mathrm{CL}=\text { then }}
\end{array}
$$

'It was just Sergio who came then.' (Txt)

(Lit. 'Sergio was just (who) came then.')

The analysis of the CC be 'ëha'mba 'he came then' in (22) as a headless relative clause equivalent to English 'who came then' may come as a puzzling analysis for some readers, mainly because there is the typological expectation that headless relative clauses are introduced by some type of relative pronoun that identifies the role of the entity to which the relative clause refers to. In European languages, such relative pronouns are recruited from wh-words (Caponigro, 2003, Caponigro et al. 2013, etc.). However, the type of relative clause encoding the CC in (22) is an asyndetic relative clause, i.e., it is not introduced by a linking element. This is, however, fully coherent with the syntax of relative clauses in Tilapa Otomi: not only headed relative clauses can be asyndetic, like in (23) (where the head nominal appears in italics), but also canonical headless relative clauses. This is shown in (24): In (24a), the clause stands for the subject argument; in (24b) for the object, ${ }^{15}$ and in (24c) for the oblique stimulus.

$$
\begin{aligned}
& \text { a. má ='mbwu nt'a rú } \quad \text { ts } \ddot{u} \quad \text { [rá=ndö] }
\end{aligned}
$$

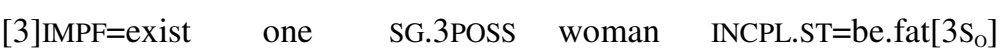

$$
\begin{aligned}
& \text { 'He had a wife who was fat.' (Txt) } \\
& \text { (Lit. 'His wife who was fat existed.') }
\end{aligned}
$$

\footnotetext{
${ }^{15}$ An anonymous referee suggested the possibility that example (24b) was perhaps an instance of two clauses linked by parataxis (i.e., [it (the food) was off] (and) [I gave it to it (the dog)]). Whether such paratactic structures are possible in Otomi, such a construction would have a distinctive prosody of its own. The way example (24b) was prosodically rendered suggests that the headless relative was indeed treated as a constituent of the main clause, because the speaker embedded it within the same prosodic contour that is used in clauses with fronted phrases. I want to thank the anonymous referee for raising this important point.
} 

b. $\quad b i=z \underline{o x}=a$
a
${ }^{h} p a \quad[\mathrm{bi}=\mathrm{ty} \ddot{\mathrm{u}}=\mathrm{a}]$
[3]CPL $=S S /$ arrive.there. $\mathrm{AS}=\mathrm{CL} \quad$ DEF.SG day $\quad[3] \mathrm{CPL}=\mathrm{SS} / \mathrm{die}=\mathrm{CL}$
'The day when he was dead arrived.' (Txt)
a. $\quad \operatorname{hin}=a ́$
$\mathrm{za}$
[rati
kha]
NEG=INCPL.ST be.good
[3]INCPL
do
'What he does is not good.' (Txt)
b. $\quad[x p i=$ etxa_perder $] \quad$ tú $=$ 'uny $=\mathrm{a}$
[3]PRF=get.off 1.CPL=give.to.3.AS[3OBJ]=CL

'I gave it (the dog) what was off.' (Txt)
c. porke túdú $\quad{ }^{\mathrm{h}} \mathrm{tsü}=\mathrm{a} \quad\left[\mathrm{bi}=\mathrm{mbe}^{\mathrm{h}}{ }^{\mathrm{h} i-g i}\right]$
because 1.CPL get.scared $=\mathrm{CL} \quad$ [3] $\mathrm{CPL}=\mathrm{SS} / \mathrm{tell}-1 \mathrm{DAT}$
'Because I got scared of what he told me.' (Txt)

In the light of the broader context of relative clause syntax, it is sensible to sustain that the $\mathrm{CC}$ in a cleft in Tilapa Otomi is a headless relative clause. There are two other minor arguments in favor of such a treatment. ${ }^{16}$

On one hand, the $\mathrm{CC}$ shows the syntax of extraction proper of relative clauses. To illustrate this, consider the different inflectional formatives used in the predicate of the asyndetic relative clauses in (25a) and (25b). In (25a), the head works as the object of the relative clause, while in (25b), the head is the instrument. In (25b), the formative comes from a special paradigm that we can call 'adverbial inflection', which has an applicative registration function (see Hernández-Green, 2016), and which is used in cases like (25b), when the relativized position is that of instrument or manner. Example (26) shows that the same inflection applies in clefts, suggesting that the morphosyntax of the asyndetic CC in (26) responds to similar syntactic requirements of extraction as the relative clause in (25b).
a. giti 'nah-k $\underline{u} \approx n i=r$
txühme $\left[\mathrm{ta}=\mathrm{ta}^{\mathrm{h}} \mathrm{ki}\right.$
OBJ $\}]$

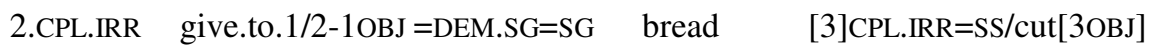
'Give me the bread that she's going to cut.' (Elic.)

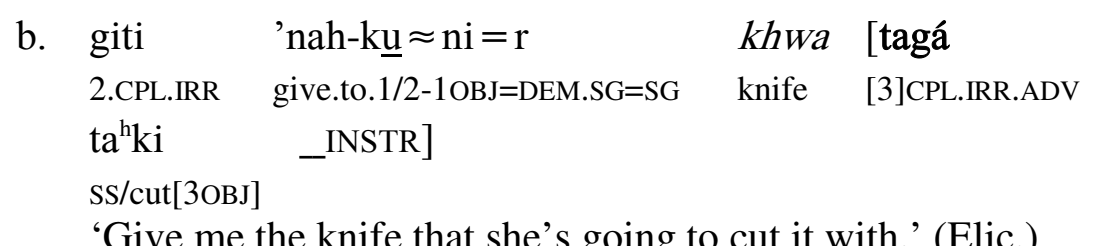

(26)
$\mathrm{kẹh}=\mathrm{a}=\left[\mathrm{k}^{\prime} \underline{\mathrm{u}}\right]_{\mathrm{FP}} \quad\{$ taga
'mbebi-k'y $=\mathrm{a} \quad$ INSTR $\}_{\mathrm{CC}}=$ 'k $\underline{\mathrm{u}}$
COP.AS $=\mathrm{CL}=3 \mathrm{PL}_{\mathrm{PRO}}$
[3]CPL.IRR.ADV SS/hit-2[SG]OBJ=CL=3PL PRO
'It's them (the branches) that she's going to beat you with.' (Txt)
(Lit. 'They are what she's going to beat you with.')

On the other hand, when the FP is a locative, the CC is introduced by the locative relative pronoun 'abw $\underline{u}$ 'where', like in (27a). An example of a headed relative clause with 'abw $\underline{u}$ 'where' is given in (27b). The occurrence of the same relative pronoun in both structures bears support for the treatment of asyndetic CCs as relative clauses.

\footnotetext{
${ }^{16}$ Furthermore, treating the $\mathrm{CC}$ as a relative clause makes Otomi syntax coherent with what is expected of clefts from a cross-linguistic perspective. In this connection, in their typology of clefts, Drubig and Schaffar (2001) conclude that the only existing agreement about clefts in the literature is that the subordinate structure encoding the background is some sort of a relative clause. Such a view stems from Schachter (1973) and is continued in the pragmatic-syntactic approach in Lambrecht (2001:467).
} 

a. $\mathrm{kẹh}=\mathrm{a}[=\mathrm{gwa}]_{\mathrm{FP}}$
\{'abwu
$\mathrm{bi}=\mathrm{zo}\}_{\mathrm{CC}}$
COP.AS $=\mathrm{CL}=$ here
WHERE
$[3] \mathrm{CPL}=\mathrm{SS} / \mathrm{fall}$

'It's here where he fell.' (Txt)

(Lit. 'Here is where he fell.')

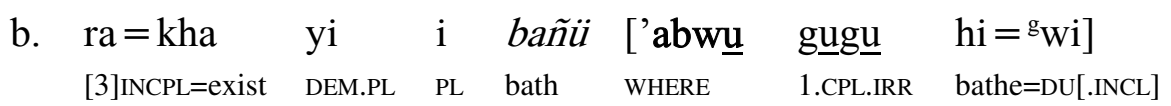

'There are these baths where we may have a bath.' (Txt)

The CC in (27a) is a headless relative clause introduced by a wh-word. The language allows for other wh-words to introduce other types of headless relative clauses, like in (28), but such clauses are not allowed as CC in clefts. ${ }^{17}$ This is shown by the ungrammaticality of (29).

a. 'ne $=\mathrm{a} \quad$ ru $\quad$ hony $=\mathrm{a} \quad[$ to $=\mathrm{r} \underline{u} \quad \tilde{\text { nöny }}=\mathrm{a}]$

and=CL $[3] \mathrm{HAB} \quad$ search. $\mathrm{AS}=\mathrm{CL} \quad$ WHO=[3]HAB help.AS[3OBJ]=CL

'And she's looking for someone who may help her.' (Txt)

(Lit. And she's looking for who may help her.')

b. $\mathrm{ti}=$ presenta $=\mathrm{k} \underline{\mathrm{u}} \quad[$ te trámáti $\quad \mathrm{kha}=$ 'mbe $=\mathrm{gwa}]$

[3]CPL.IRR=present=there WHAT 1.INCPL.IMPF $\quad$ do=PL.EXCL=here

'She would present what we used to do here.' (Txt)

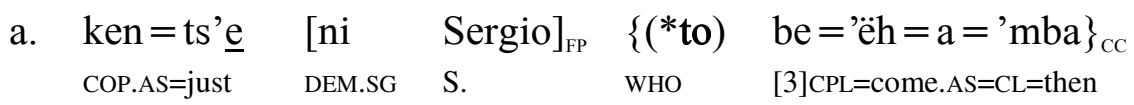

'It just was Sergio who came then.' (Txt)

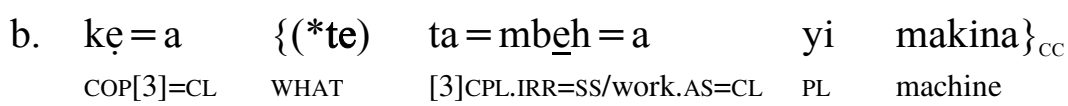

'It's what the machines are going to do.' (Txt)

\subsection{Special features of Tilapa Otomi clefts}

Clefts in Tilapa Otomi may have two more peculiarities. The first one is specifically Otomi and it involves the occurrence of a pronominal enclitic in the construction to cross-reference the FP (for more details, see Palancar 2018b). The second one has to do with fronting the FP before the copula.

\section{Pronouns cross-referencing the FP:}

More often than not, clefts in Otomi have a pronoun that cross-references the FP and that occurs at the right-edge boundary of the construction. This is illustrated in (30), where the enclitic of 3rd person singular =' $a$ cross-references the FP 'Pope Boniphace' and it is placed at the end of the utterance.
(30)

kẹh=a $\quad[a \quad \text { Papa Boniphasio }]_{\mathrm{FP}}$
COP.AS=CL DEF.SG Pope Boniphace
'It was Pope Boniphace that did it.' (Txt)
(Lit. 'Pope Boniphace was who did it.')

Clefts are based on the specificational copular construction. The pronominals occurring at the right-edge of clefts are a characteristic property of the copular construction, as illustrated in (31).

\footnotetext{
${ }^{17}$ There is a difference between the relative pronoun strategy in (27) and in (28). The relative pronoun strategy in (27) is the only possible way to relativize a locative adjunct, so clefts, like the one in (27a), cannot do without the locative pronoun strategy. For the relativization of arguments, asyndetic clauses are the norm. Why the relative pronoun strategy in (29) is not allowed in CCs remains an open question.
} 


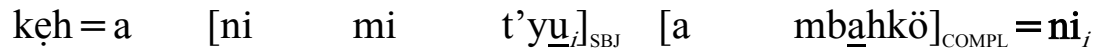

$$
\begin{aligned}
& \text { COP.AS }=\text { CL DEM.SG } 1 \text { PPOSS son DEF.SG priest=DEM.SG } \mathrm{PRO}_{\mathrm{PRO}}
\end{aligned}
$$

When the FP is itself a pronominal, the default is that the cross-referencing pronoun is a copy of the FP, as shown in (32). When the FP is a DP, the enclitic copies the head determiner. This can be seen in the copular construction in (31).
a. $\quad \mathrm{kẹ}=\mathrm{a}=\left[\mathrm{k}^{\prime} \underline{\mathrm{u}}_{i}\right]_{\mathrm{FP}} \quad\{\text { giti } \quad \text { gosa }=\mathrm{wi}\}_{\mathrm{CC}}=\mathrm{k}^{\prime} \underline{\mathrm{u}}_{i}$ $\mathrm{COP}=\mathrm{CL}=3 \mathrm{PL}_{\mathrm{PRO}} \quad$ 2.CPL.IRR $\quad$ enjoy $=2 \mathrm{PL}=3 \mathrm{PL}_{\mathrm{PRO}}$

'It's those ones you (PL) are going to enjoy.' (Txt)

(Lit. 'Those are the ones you (PL) are going to enjoy.')
b. $\mathrm{keh}=\mathrm{a}=\left[\mathrm{ni}_{j_{\mathrm{FP}}} \quad\left\{\mathrm{bi}={ }^{\prime}\right.\right.$ '̃ën $=\mathrm{ga}_{\mathrm{CC}}=\mathrm{ni}_{i}$ COP. $. \mathrm{AS}=\mathrm{CL}=\mathrm{DEM} . \mathrm{SG}_{\mathrm{PRO}} \quad[3] \mathrm{CPL}=\mathrm{SS} / \mathrm{say} \cdot \mathrm{AS}=1[\mathrm{SG}]=\mathrm{DEM} \cdot \mathrm{SG}_{\mathrm{PRO}}$ 'It's her who told me.' (Txt)

Although examples like (32) are the norm, it may happen that the copula bears no pronoun, like in (33), but there is still a pronominal enclitic standing for the covert FP. In such cases, the enclitic is the only instantiation of the FP in the clause.

$$
\begin{array}{lll}
\text { kẹh }=\mathrm{a} & {\left[{ }_{-i}\right]_{\mathrm{PP}}} & \{\mathrm{bi}=\text { mbita }=\mathrm{gi}=\mathrm{h} \underline{\mathrm{u}}\}_{\mathrm{CC}}=\left[{ }^{\prime} \ddot{\mathrm{a}}_{i}\right]_{\mathrm{FP}} \\
\text { COP.AS}[3]=\mathrm{CL} & {[3] \mathrm{CPL}=\text { invite }=1 \mathrm{ACC}=\mathrm{PL} . \mathrm{INCL}=3 \mathrm{SG}_{\mathrm{PRO}}}
\end{array}
$$

'It's him who invited us.' (Txt)

The pronominals occur at the right-edge of the cleft construction. This means that they are not morphosyntactically associated with the $\mathrm{CC}$ in a direct way (i.e., they are not resumptive pronouns inside the CC). Examples (34) are evidence for this analysis. The enclitics cannot be syntactically associated with nouns, so when one finds them on a noun, they are just taking the noun as a phonological host. This happens in both (34a) and (34b). Example (34a) could still be analyzed as if the enclitic occurred to the right-edge of the $\mathrm{CC}$; that is, as internal to it. In contrast, example (34b) shows that this cannot be the case, because it is associated to the FP. Example (34b) is also a very rare case where the CC has been fronted over the copula.

$$
\begin{array}{ll}
\text { a. } & \mathrm{keh}=\mathrm{a} \quad\left\{\mathrm{gi}={ }^{\mathrm{h}} \mathrm{kö} ' \underline{\mathrm{u}} \approx \mathrm{nt}\right. \\
\text { COP.AS}[3]=\mathrm{CL} & \text { 2.CPL.IRR=pour.inside.container.AS[3OBJ] } \approx \mathrm{IND} . \mathrm{SG} \\
\text { t'oni }\}_{\mathrm{CC}}=\left[{ }^{\prime} \mathrm{a}\right]_{\mathrm{FP}} \\
\text { cup }=3 \mathrm{SG}_{\mathrm{PRO}} \\
\text { 'That's what you pour into a cup.' }(\mathrm{Txt})
\end{array}
$$

b. $\left\{\mathrm{bw} \underline{\underline{u}}={ }^{\mathrm{h}} \mathrm{t} \underline{\underline{u}} \underline{\mathrm{h}}=\mathrm{w} \underline{\mathrm{u}}=\mathrm{gwa}\right\}_{\mathrm{CC}} \quad \mathrm{kẹh}=\mathrm{a} \quad\left[\begin{array}{lll}\mathrm{ni} & \mathrm{mi}\end{array}\right.$ [3]CPL.VEN=catch.AS=DU.AS=here COP.AS=CL DEM.SG 1 PPOSS $\left.\mathrm{t}^{\prime} \mathrm{ixu}_{i}\right]_{\mathrm{FP}}=\mathrm{a}=\mathrm{ni}_{i}$ daughter $=\mathrm{CL}=\mathrm{DEM} . \mathrm{SG}_{\mathrm{PRO}}$

'The one who came here to catch up with him was my daughter.' (Txt)

\section{Fronting FPs:}

Clefts may have a fronted FP. When this happens, the fronted phrase necessarily occurs with the particle $\tilde{n} \ddot{u}$, like in (35) (except when it is possessed phrase, in which case it is commonly not used).

$$
\begin{array}{llll}
\text { a. } & {[\tilde{n} \ddot{u}=a]_{\mathrm{FP}}} & \text { kẹh }=\mathrm{a} & \left\{\mathrm{bi}={ }^{\mathrm{h}} \text { pasa }\right\}_{\mathrm{CC}} \\
& {\text { PRTCL }=3 \mathrm{SG}_{\mathrm{PRO}}} & \text { COP.AS=CL } & {[3] \mathrm{CPL}=\text { undergo }}
\end{array}
$$


'THAT's what he underwent.' (Txt)
b. pero $\quad\left[\tilde{\mathrm{n}} \ddot{\mathrm{u}}=\mathrm{a}=\mathrm{ya}_{\mathrm{i}}\right]_{\mathrm{FP}} \quad \mathrm{ke}=\mathrm{a} \quad\{$ giti
but $\quad$ PRTCL $=C L=D E M . P L_{P R O} \quad C O P=C L \quad$ 2.CPL.IRR.ADV polish.AS[3OBJ]=DEM.PL ${ }_{\text {PRO }}$
'It's THOSE (things) what you're going to polish it with.' (Txt)

In example (16b) above, repeated here as (36), we had seen that pronouns could occur fronted without $\tilde{n} \ddot{u}$, when they are topical. This never happens when they are fronted in a cleft, as shown by the ungrammaticality of (37), suggesting that pronominal elements in focus require nü.

$$
\begin{array}{lll}
\text { mientras }=\text { ga } & \mathrm{gu}={ }^{\prime}=\underline{\mathrm{ot}}^{\prime} \underline{\mathrm{u}} \approx \mathrm{ni} & { }^{\prime} \mathrm{i} \\
\text { while }=1[\mathrm{SG}]_{\mathrm{PRO}} & \text { 1.CPL.IRR }=\text { make.AS } \approx \text { DEM.SG } & \text { Food }
\end{array}
$$

'While I will make the food' (Txt)

$$
\begin{aligned}
& *_{\text {pero }}=\left[\mathrm{ya}_{i}\right]_{\mathrm{FP}} \quad \mathrm{ke}=\mathrm{a} \quad\{\text { giti } \quad \text { k'oti }=\mathrm{a}\}_{\mathrm{CC}}=\mathrm{ya}_{i} \\
& \text { but }=\text { DEM.PL } L_{\text {PRO }} \quad \mathrm{COP}=\mathrm{CL} \quad \text { 2.CPL.IRR.ADV polish.AS[3OBJ]=DEM.PL } \text { PRO }_{\text {PRO }} \\
& \text { Intended reading: 'It's THOSE (things) what you're going to } \\
& \text { polish it with.' }
\end{aligned}
$$

We have seen the cleft construction in Tilapa Otomi in detail. In the following section, I introduce another specialized focus construction that is monoclausal, but which could be mistaken as a cleft. The purpose of the following section is to introduce two arguments that support its treatment as a monoclausal construction.

\section{The fronting focus construction}

Besides the examples of clefts that we have seen so far, there are other instances of focus utterances in Tilapa Otomi which involves fronting the FP. Two examples are given in (38). ${ }^{18}$

$$
\begin{aligned}
& \text { a. } \quad\left[\begin{array}{llllll}
\text { nü } & \text { sku } & \mathrm{xu}^{\mathrm{h}} \mathrm{tsi}
\end{array}\right]_{\mathrm{FP}} \text { ko adí } \quad \text { zony }=\mathrm{a} \\
& \text { PRTCL DIM girl HUM.FOC [3]INCPL.AMBU weep.AS=CL }
\end{aligned}
$$

'THE GIRL goes about weeping.' (Txt)

(Lit. 'The girl, SHE goes about weeping.' (Txt)

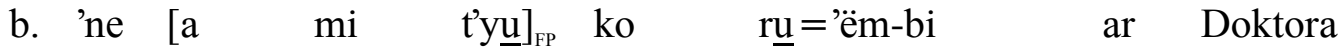

$$
\begin{aligned}
& \text { and DEF.SG } 1 \text { PPOSS son HUM.FOC [3]HAB=say.AS-3DAT SG Doctor } \\
& \text { 'And MY SON tells the doctor.' (Txt) } \\
& \text { (Lit. 'And my son, HE tells the doctor.') }{ }^{19}
\end{aligned}
$$

Apart from the requirement of fronting the FP, this focus construction further involves the element $k o$, which I gloss here as 'human focus'. This element $k o$ can also be found in the CC of a cleft when the FP is a human being, as shown in (39). ${ }^{20}$ The ungrammaticality of (40) further shows that $k o$ cannot be used when the FP is inanimate.

\footnotetext{
${ }^{18}$ Example (38b) is an example of a DP including a possessed noun that is not introduced by the particle $\tilde{n} \ddot{u}$.

${ }^{19}$ It is difficult to translate examples of the fronting focus construction in English. I have opted to translate most of the examples in two ways. One where the focus phrase is rendered in small caps, and another one where the focus phrase is rendered as if it were a fronted topical participant that is then taken up as the focus of the clause.

${ }^{20} \mathrm{An}$ anonymous reviewer questioned the reason for my assumption that $k o$ occurs in the CC by asking why one could not assume that it forms part of the fronted FP or as a functional head of its own, a focal projection in the left periphery, to the specifier of which the FP moves to. I do not thing that such an analysis is viable for Tilapa Otomi. First, in §4.2 I give some irrefutable evidence from the marking of negation that $k o$ occurs in the CC. Second, all other functional heads in Otomi are phrase initial. In the same way, if ko were a focus marker opening a projection, one would expect that it preceded the noun in focus, just like the particle ñü. Finally, a string consisting of a FP followed by ko can neither be uttered within the same prosodic phrasal contour nor behave like a syntactic constituent.
} 
$\begin{array}{lllll}\text { a. hi'na, } & \mathrm{keh}=\mathrm{a} & {[\mathrm{na}} & \mathrm{mi} & \left.\text { mimukha }_{i}\right]_{\mathrm{FP}} \\ \text { no } & \text { COP.AS=CL} & \text { DEM.SG } & 1 \text { PPOSS } & \text { sister.in.law }\end{array}$

$\left\{\text { ko } \quad \text { bi }={ }^{\text {h }} \text { pat'y }=\mathrm{a}\right\}_{\mathrm{CC}}=$ na $_{i}$

HUM.FOC 3]CPL=burn[3OBJ] $=$ CL $=$ DEM.SG PRO $_{\text {Ro }}$

'No, it was this sister-in-law of mine who burned it (the

hut).' (Txt)

b. $\mathrm{keh}=\mathrm{a} \quad\left[\mathrm{ni} \quad \mathrm{mi} \quad \mathrm{t}^{\prime} \mathrm{y} \underline{\mathrm{u}}\right]_{\mathrm{FP}} \quad\{\mathrm{ko} \quad \text { bi }=\mathrm{xojx}=\mathrm{a}\}_{\mathrm{CC}}$

COP.AS=CL DEM.SG 1 PPOSS son HUM.FOC [3]CPL=lift.AS[3OBJ]=CL

'It was My son who built it up again.' (Txt)

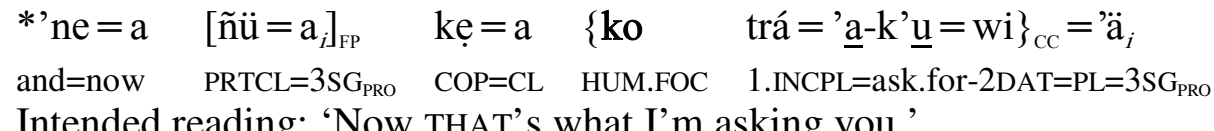

The fact that ko has anaphoric semantics attending to an animacy feature of the participant in focus suggests that $k o$ is a pronoun. Palancar (2018a) refers to this pronominal element as the 'focus extraction pronoun', because it is only found in focus constructions. ${ }^{21}$ Similarly, the fact that $k o$ is obligatory in the fronting focus construction is coherent with its pronominal status, because in constructions like these where focus fronting is seen as involving some type of syntactic movement, it would not be unexpected to have a resumptive pronoun. The only typological oddity of Tilapa Otomi is that the construction involves a specialized pronoun that pragmatically informs that the human noun to which it refers back is in focus in the clause.

Palancar (2018a) treats examples like (38) as instances of the cleft construction that have no overt copula. This analysis is based on various facts. They resemble instances of clefts with fronted FPs like the ones in (35) and they bear the element $k o$, just like other clefts do. Besides, in the specificational construction, the copula can be elided, as shown in (41). All this led Palancar to interpret that an instance like (38a) has the structure in (42).

$$
\begin{array}{clll}
\text { 'ne }=\mathrm{a}\left[=\mathrm{ni}_{i}\right]_{\mathrm{SBJ}} & \varnothing & {[\mathrm{a}} & \mathrm{mb}^{\mathrm{h}} \mathrm{kö}_{\mathrm{COMPL}}=\mathrm{ni}_{i} \\
\text { and }=\mathrm{CL}=\mathrm{DEM}_{\mathrm{SG}} & \text { COP } & \text { DEF.SG } & \text { priest=DEM.SG }
\end{array}
$$

'And he's the priest.' (Txt)

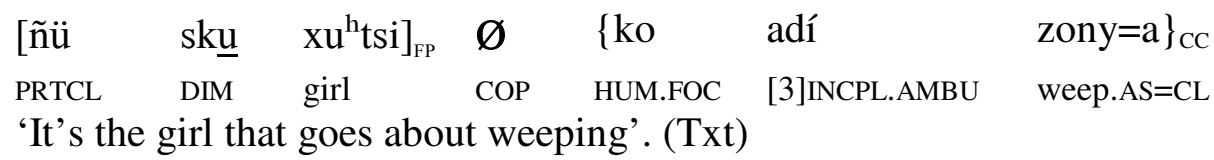

In this paper, however, I argue that despite their resemblance with clefts, examples like (38) are not instances of the cleft construction in (39). Instead, I propose that they instantiate a different focus construction that is monoclausal and involves fronting the FP to a prepredicate position. I refer to this construction as the 'fronting focus construction'. In the

\footnotetext{
${ }^{21}$ Palancar (2018a) refers to this pronominal element as the 'focus extraction pronoun', because it is only found in focus constructions. For example, it is not a relative pronoun as it cannot be used in neither headed nor headless relative clauses, as shown in (i.a) and (i.b), respectively.
(i) a. 'ne trá="ëm-bi i khåni [to/*ko má=xọx =a]
and 1.INCPL=say.AS-3DAT PL man WHO/HUM.FOC [3] IMPF=lift.AS[3OBJ]=CL
'And I tell the men who were lifting her...' (Txt)
b. $\quad$ ne $=\mathrm{a} \quad \mathrm{r} \underline{\mathrm{u}}=\mathrm{hony}=\mathrm{a} \quad\left[\right.$ to $/{ }^{*} \mathrm{ko} \quad$ ru $\left.=\tilde{\mathrm{n}} \mathrm{öny}=\mathrm{a}\right]$
and $=\mathrm{CL} \quad[3] \mathrm{HAB}=$ search. $\mathrm{AS}=\mathrm{CL} \quad$ WHO/HUM.FOC $\quad[3] \mathrm{HAB}=$ search. $\mathrm{AS}[3 \mathrm{OBJ}]=\mathrm{CL}$
'And she's looking for someone who may help her.' (Txt)


following sections I elaborate on the evidence that supports an analysis of this construction as being monoclausal.

\subsection{The fronting focus construction is not based on the copular construction}

Unlike clefts, the fronting focus construction is not based on the copular construction and it is thus monoclausal. If that were the case, a zero copula could be reinstated by an overt copula, but it cannot. This is shown when an example like (35a), repeated here as (43a), which is a fine example of a cleft with a fronted FP, is contrasted with (43b), which is ungrammatical. This means that the analysis in (42) cannot be right.

$$
\begin{aligned}
& \text { a. } \quad[\tilde{n} \ddot{u}=a]_{\mathrm{FP}} \quad \mathrm{kẹh}=\mathrm{a} \quad\left\{\mathrm{bi}={ }^{\mathrm{h}} \text { pasa }\right\}_{\mathrm{CC}} \\
& \text { PRTCL }=3 S_{\mathrm{PRO}_{\mathrm{PRO}}} \quad \mathrm{COP} . \mathrm{AS}=\mathrm{CL} \quad[3] \mathrm{CPL}=\text { undergo }
\end{aligned}
$$

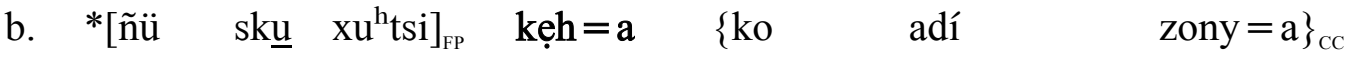

$$
\begin{aligned}
& \text { PRTCL DIM girl COP.AS=CL HUM.FOC [3]INCPL.AMBU weep.AS=CL } \\
& \text { Intended reading: 'It's the girl that goes about weeping'. }
\end{aligned}
$$

In my documentary corpus of the language, there are examples like (44) which are related to (43b), but only apparently. In all such cases, the FP is clearly extracted to the left of the clause. This can be seen by way of two facts: one is the occurrence of a resumptive pronoun associated to the copula, which anaphorically refers back to extracted FP; the other is the prosodic contour, where the FP is split from the intonational unit that encodes the rest of the utterance.

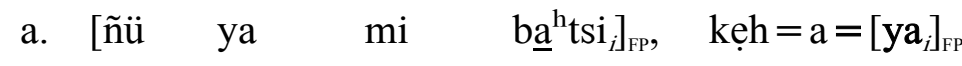

$$
\begin{aligned}
& \text { PRTCL DEM.PL } 1 \text { PPOSS child COP.AS=CL=DEM.PLPRO }
\end{aligned}
$$

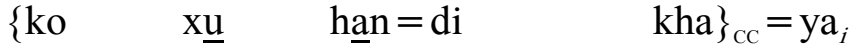

$$
\begin{aligned}
& \text { HUM.FOC indeed AGAIN=[3]CPL.IRR do[3OBJ]=DEM.PL } L_{\text {PRO }} \\
& \text { 'My sons, it's them that will do it again.' (Txt) } \\
& \begin{array}{lllll}
\text { b. } & \text { pero } \quad[\tilde{n} \ddot{u} & \text { a } & \text { me } & \left.{ }^{\mathrm{h}} \mathrm{Tila}^{\mathrm{h}} \mathrm{pa}_{i}\right]_{\mathrm{FP}}, \\
\text { but } & \text { PRTCL } & \text { DEF.SG } & \text { HUM.CLF } & \text { T. } \\
\text { kẹh }=\mathrm{a}=\left[{ }^{\prime} \ddot{a}_{i}\right]_{\mathrm{FP}} & \{\text { ko } & \text { bi }=\text { salba }\}_{\mathrm{CC}}=\dddot{a}_{i} \\
\text { COP.AS=CL=3SG } & \text { HUM.FOC } & {[3] \mathrm{CPL}=\mathrm{save}[3 \mathrm{OBJ}]=3 \mathrm{SG}_{\mathrm{PRO}}}
\end{array}
\end{aligned}
$$

'But the person from Tilapa, that's the one who saved him.' (Txt)

Secondly, unlike clefts, instances of the fronting focus construction do NOT take a pronominal enclitic. I interpret this constraint to be a proof that the fronting focus construction is not based on the copular construction and it is thus monoclausal. For this compare (45) with its pragmatic equivalent in (46), which would be ungrammatical with the enclitic.

$$
\begin{array}{lllll}
\operatorname{ken}\left[=\mathrm{ga}_{i}\right]_{\mathrm{FP}} & \{\text { ko } & \mathrm{gw} \underline{\mathrm{u}}=\text { testiga } & \text { 'a } & \text { nikhö }\}_{\mathrm{CC}}=\mathbf{g a}_{i} \\
\text { COP.AS=1[SG }]_{\mathrm{PRO}} & \text { HUM.FOC } & 1 . \mathrm{CPL} . \mathrm{IRR} . \mathrm{VEN}>\text { EXLOC=testify } & \mathrm{P} & \text { church }=1[\mathrm{SG}]_{\mathrm{PRO}} \\
\text { 'It's me who's going to testify at church.' (Elic.) } & &
\end{array}
$$

$$
\begin{aligned}
& {\left[\tilde{n} \ddot{u}=\mathrm{ga}_{i}\right]_{\mathrm{FP}} \quad\{\text { ko } \quad \text { gw } \underline{u}=\text { testiga } \quad \text { 'a nikhö }\}_{\mathrm{CC}}\left(*=\mathrm{ga}_{i}\right)} \\
& \text { PRTCL }=1[\mathrm{SG}]_{\mathrm{PRO}} \quad \text { HUM.FOC } 1 . \mathrm{CPL} . I R R . V E N>\text { EXLOC=testify } \quad \mathrm{P} \quad \text { church }=1[\mathrm{SG}]_{\mathrm{PRO}} \\
& \text { 'I am going to testify at church.' (Txt) } \\
& \text { (Lit. 'Me, I am going to testify at church.') }
\end{aligned}
$$

The two focus constructions, the cleft construction and the fronting focus construction, could be said to be pragmatically equivalent, but the latter is only used when the FP is a human being. In contrast, clefts impose no conditions as to the type of entity to be treated as FP. 
When the focus is human, the fronting focus construction is also the default encoding option when the FP is a personal pronoun, like in (46) when compared to (45). This means that examples like (45), while possible, are not attested in the corpus. In complementary distribution, fronted pronominal FPs in clefts, like the one in (47), are only allowed when the FP is inanimate. This produces the nice contrast regarding animacy. For this, compare (47) and (48).

$$
\begin{aligned}
& \text { 'ne }=\mathrm{a} \quad\left[\tilde{n} \ddot{\mathrm{u}}=\mathrm{a}_{i}\right]_{\mathrm{FP}} \quad \mathrm{kẹ}=\mathrm{a} \quad\left\{\text { trá }={ }^{\prime} \underline{\mathrm{a}}-\mathrm{k} \underline{\mathrm{u}}=\mathrm{wi}\right\}_{\mathrm{CC}}=\dddot{\mathrm{a}}_{i} \\
& \text { and=now } \quad P R T C L=3 S_{G_{P R O}} \quad C O P=C L \quad 1 . I N C P L=a s k . \text { for }-2 D A T=P L=3 S_{\text {PRO }}
\end{aligned}
$$

'Now THAT's what I'm asking you.' (Txt)

$$
\begin{aligned}
& {\left[\tilde{\mathrm{n}} \ddot{\mathrm{u}}=\mathrm{a}_{i}\right]_{\mathrm{FP}} \quad \mathrm{ko}_{i} \quad \mathrm{ko}_{i} \quad \mathrm{ti}={ }^{\mathrm{h}} \mathrm{pe} \mathrm{t}^{\mathrm{i}} \mathrm{i}} \\
& \mathrm{PRTCL}=3 \mathrm{SG}_{\mathrm{PRO}} \quad \text { HUM.FOC } \quad \text { [3] CPL.IRR=make.tortillas }
\end{aligned}
$$

\subsection{The fronting focus construction and negation}

The behavior of negation is another important criterion to determine that the fronting focus construction is monoclausal. In a cleft, when speakers want to cancel the referent of the FP as a possible alternative, they negate the copula. This is shown in (49) with the occurrence of the adverb hing $\underline{u}$, which is used to negate non-verbal predicates. ${ }^{22}$

$$
\begin{aligned}
& \text { hingu } \quad \mathrm{ken}=\left[\mathrm{k}^{\prime} \mathrm{u}_{i}\right]_{\mathrm{FP}} \quad\{\text { grá }=\mathrm{tsix}-\mathrm{ki}\}_{\mathrm{CC}}=\mathrm{k}^{\prime} \mathrm{u}_{i} \\
& \text { NEG COP.AS=over.there 2.INCPL=take.AS-2ACC }=\text { over.there } \\
& \text { 'It's not there where you're taking me.' (Txt) }
\end{aligned}
$$

In contrast, when they want to negate the alternative in (50), they cannot negate the FP, as if it were a predicate. This is shown by the infelicity of (51). In contrast, they negate the main predicate, like in (52). I take this behaviour as an indisputable proof that the fronting focus construction is monoclausal.

$$
\begin{aligned}
& {[\tilde{n} \ddot{u}=\mathrm{ga}]_{\mathrm{FP}} \quad \text { ko } \quad \text { trá }=\text { '̈u }^{\mathrm{h}} \underline{\mathrm{u}}=\mathrm{ga} \quad \text { ra } \quad \tilde{\text { nühü }}} \\
& \text { PRTCL }=1[\mathrm{SG}]_{\text {PRO }} \quad \text { HUM.FOC } \quad 1 . \mathrm{INCPL}=\text { teach }=1[\mathrm{SG}]_{\mathrm{PRO}} \quad \text { SG } \quad \text { Otomi } \\
& \text { 'I am teaching Otomi.' (Txt) }
\end{aligned}
$$

(Lit. 'Me, I am teaching Otomi.')

$$
\begin{aligned}
& \text { *hingu }[\tilde{\mathrm{n}} \ddot{u}=\mathrm{ga}]_{\mathrm{FP}} \quad \text { ko } \quad \text { trá }=\mathfrak{u ̈}^{\mathrm{h}} \underline{\mathrm{tu}}=\mathrm{ga} \quad \text { ra } \tilde{\text { nühi }} \\
& \text { NEG PRTCL }=1[\mathrm{SG}]_{\mathrm{PRO}} \text { HUM.FOC 1.INCPL=teach }=1[\mathrm{SG}]_{\mathrm{PRO}} \text { SG Otor } \\
& \text { Intended reading: 'I am not teaching Otomi.' }
\end{aligned}
$$

$$
\begin{aligned}
& {[\tilde{\mathrm{n} u ̈}=\mathrm{ga}]_{\mathrm{FP}} \quad \text { hin }=\mathrm{kc} \text { trá }=\mathfrak{u ̈}^{\mathrm{h}} \underline{\mathrm{tu}}=\mathrm{ga} \quad \text { ra } \tilde{\text { nühü }}} \\
& \text { PRTCL }=1[\mathrm{SG}]_{\mathrm{PRO}} \quad \text { NEG=HUN } 1 . \mathrm{INCPL}=\text { teach }=1[\mathrm{SG}]_{\mathrm{PRO}} \quad \mathrm{SG} \quad \text { Otomi }
\end{aligned}
$$

'I am not teaching Otomi.'

(Lit. 'Me, I am not teaching Otomi.')

An example like (52) additionally shows that the focus pronoun ko occurs in the Pre-V zone (see \$2.3) of the predicate of the CC..$^{23}$ This pronoun is only used in focus constructions, in such a way that its occurrence is a powerful token to inform the addressee that they are witnessing a focus construction. This is so, to such an extent that the fronting focus

\footnotetext{
${ }^{22}$ An example of another non-verbal predicate is (i).

(i) pwes si, hingu pọngi well yes NEG much(Q)

'Well yes, it's not much.' (Txt)

${ }^{23}$ As for the structure of clefts, this also means that $k o$ does not occur in the $\mathrm{CC}$ at the high syntactic position of a relative pronoun or a complementizer.
} 
construction can be instantiated in discourse just by the CC. I elaborate on this point in the next section.

\subsection{The fronting focus construction with a covert topical FP}

Hartmann and Veenstra (2013: 2) rightly point out at situations where the FP can also be topic. This might come as a surprise to those who have a general idea that topic and focus are antagonism notions. In reality, they are not, it is just a question of what type of topic we are taking about. Consider for this, the cleft in example (53b) from Hartmann and Veenstra (2013: 2).

a. [My professor was always very supportive.]

b. It was HIM who wrote the decisive letter of recommendation.

The FP in (53b) is pronominal, but it is also in focus. The fact that it is a pronoun is already stating something about its topical status. The referent of the pronoun in (53b) is an established discourse topic that is introduced in (53a). The pronoun him refers back to the professor, whose role as agent in the writing of the letter of recommendation under discussion is asserted by the speaker as being informatively relevant. A similar situation is commonly found in natural discourse in Tilapa Otomi.

Like in (53b), the referent of the FP can be an established discourse topic, making a fully overt instantiation of it undesirable for being redundant. It is also often the case that the discourse topic is the speaker or the addressee. When this happens, in Tilapa Otomi the FP is not stated. The use of a CC bearing the focus pronoun $k o$ is enough to assert the same as the English example in (53b). This is illustrated in the textual extract in (54), which has two instances of the fronting focus construction used for contrastive focus with a covert topical FP: the first one is in (54c) and refers to the speaker asserting that it is not her who did the dishes. This opens up the suspense as to who it may have been. Then her son is introduced as a topic in (54d), only to assert in (54e) that it was him the person washing up, the alternative option contrasting to the one presented in $(54 \mathrm{~d})$.

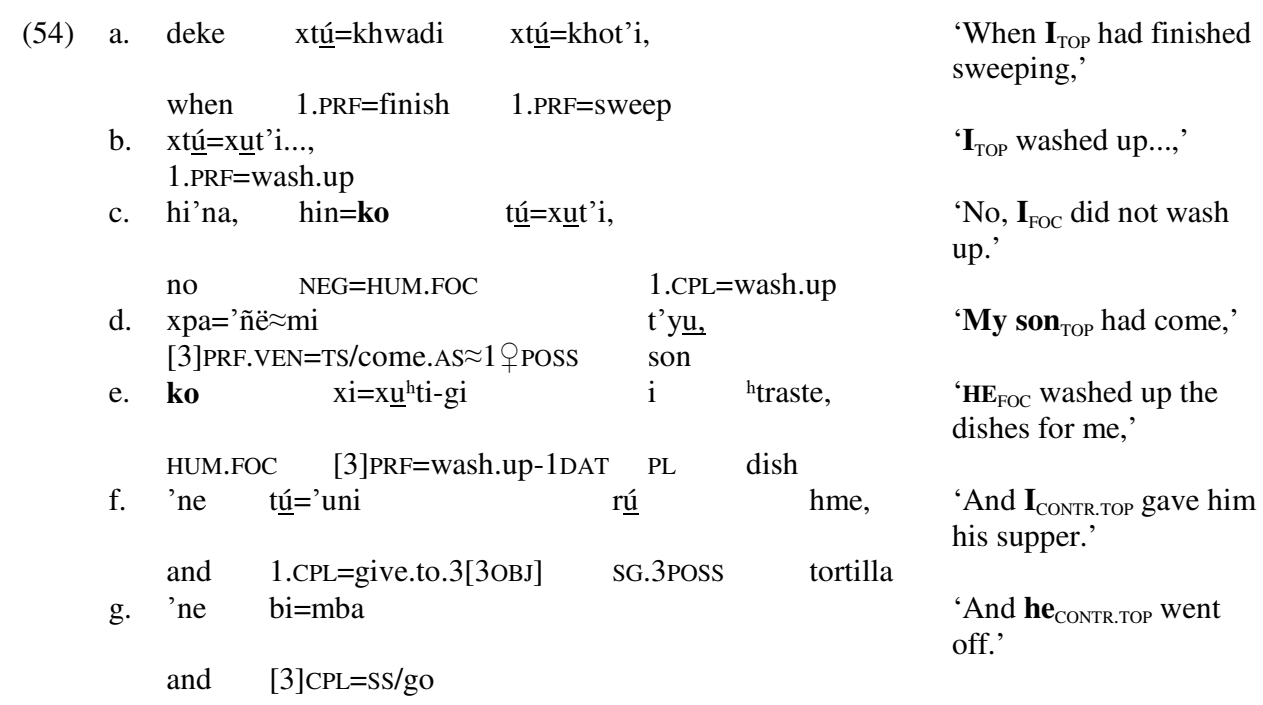

\section{Conclusions}

In this paper, I have proposed that Tilapa Otomi has (at least) two specialized focus constructions. One is a cleft construction, which is by definition biclausal. The other one, which I introduced here, is a monoclausal construction that could at a first glance pass as a cleft with a zero copula. However, the impossibility to using elements proper of the copular 
construction (i.e., reinstatement of the copula or use of pronominal enclitics) and the association of the negation to the predicate are proofs that the construction is monoclausal. This article has thus tackled the methodological problem of elucidating whether a given focus construction is a cleft or is not. The existence of two different types of focus constructions contrasting in levels of clausality, has also been recently argued for Yucatec Mayan -an unrelated Mesoamerican language to Otomi- by Verhoeven \& Skopeteas (2015), who defend the case that a construction treated as a cleft by Tonhauser (2003) and Bohnemeyer (1998) is indeed a monoclausal construction involving a fronted focus. With experimental data, these authors go onto further show that the two constructions have a seemingly different distribution. The existence of structural parallels between Otomi and Yucatec Maya involving two very similar specialized focus constructions is puzzling because the two languages have not been in known contact. One could appeal to the phenomenon having resulted from the systemic convergence proper of the dynamics of areal typology, as both families have long been considered to belong to the Mesoamerican linguistic area proposed in Campbell et al. (1986), but as we still lack the right data from other possible contact intermediary languages, we cannot advance any conclusions in that respect, and the existence may just be explained as a natural outcome from the typological range of focus constructions that languages can naturally develop.

Mayan is by far the Mesoamerican language family with a renowned literature on the syntax of focus, to add to the list Aissen (1992) is a seminal and referential work, but also Trechsel (1993), Bohnemeyer (2014), Gutiérrez Bravo (2015) and Aissen (2017). In OtoManguean, there have been studies on the syntax of focus mainly in Zapotec languages (Ward 1987; Lee 1997; Broadwell 1999; Black 2000; etc.) and Mixtec (Hollenbach 1995), but as for other branches of Oto-Manguean, such as Oto-Pamean, except for Palancar (2018a and 2018b), I am unaware of the existence of any other study on the topic. This paper is both a contribution to fill in gaps in our knowledge of the syntax and morphosyntax of focus constructions in Mesoamerican languages and an invitation to fellow Mesoamericanists to contribute towards that goal with their valuable work.

\section{Abbreviations}

(Not included in the Leipzig Glossing Rules): $=$ is used for clitics, but $\approx$ is used to represent a special type of cliticization of the verb form where the verb undergoes morphological compaction to form a prosodic unit with the first free word of a following syntactic phrase within its own clause (see Palancar, 2004, for details); o+: female speaker; ${ }^{\lambda}$ : male speaker; ADV: adverbial inflection; AMBU: ambulative; AS: morphophonologically adjusted stem (also applied to affixes); CC: clefted clause; CL: phrase-final clitic; CPL: completive; EXLOC: exlocative; DIM: diminutive; DP: determiner phrase; DTR: ditransitive stem; FP: focus phrase; HAB: habitual; HUM: human; IMPF: imperfect; PRO: pronominal; PRTCL: particle; $\mathrm{S}_{\mathrm{O}}$ : $\mathrm{S}$ of inactive predicate; SS: secondary stem; ST: stative; VEN: venitive.

\section{References}

Aissen, Judith. 1992. Topic and focus in Mayan. Language 68:43-80.

- 2017. Information structure in Mayan. Judith Aissen, Nora England \& Roberto Zavala (eds), The Mayan Languages, pp. 293-325. Milton Park: Routledge.

Angulo, Jaime de. 1933. The Chichimeco Language (Central Mexico).International Journal of American Linguistics 7(3/4): 152-194.

Black, Cheryl A. 2000. Quiegolani Zapotec Syntax: A Principles and Parameters Account. Dallas: Summer Institute of Linguistics and University of Texas at Arlington.

Broadwell, George Aaron. 1999. Focus alignment and optimal order in Zapotec. MS.

Campbell, Eric. In press. Layered complexity in Zenzontepec Chatino verbal inflectional classes. Amerindia 41: 39-74. 
Campbell, Lyle; Terry Kaufman \& Thomas-Cedric Smith-Stark. 1986. Meso-America as a linguistic area. Language 62(3): 530-70.

Caponigro, Ivano. 2003. Free Not to Ask: On the semantics of free relatives and wh-words crosslinguistically. PhD Dissertation. University of California at Los Angeles.

Caponigro, Ivano, Harold Torrence, and Carlos Cisneros. 2013. Free relative clauses in two Mixtec languages. International Journal of American Linguistics 79: 41-96.

Drubig, Hans-Bernhard and W. Schaffar. 2001. Focus constructions. In Martin Haspelmath and Ekkehard Koenig and Wulf Osterreicher (eds.), Language typology and language universals. pp. 1079-1104. Berlin: Mouton de Gruyter.

Gutiérrez Bravo, Rodrigo. 2015. Las cláusulas relativas en maya yucateco. [Estudios de Lingüística XXII]. Mexico City: El Colegio de México.

Hartmann, Katharina and Tronjes Veenstra. 2013. Introduction. In Katharina Hartmann and Tronjes Veenstra (eds.), Cleft structures, pp. 1-34. Amsterdam: John Benjamins.

Hernández-Green, Néstor. 2015. Morfosintaxis verbal del otomí de Acazulco. PhD Dissertation. CIESAS.

- 2016. Registration versus applicative constructions in Acazulco Otomi. International Journal of American Linguistics 82(3): 353-383.

- Forthcoming. Headless Relative Clauses in Acazulco Otomi. In Ivano Caponigo, Harold Torrence \& Roberto Zavala (eds.), Headless relative clauses in Mesoamerican Languages. Oxford: Oxford University Press.

Hollenbach, Barbara E. 1995. A preliminary catalogue of focus devices in Mixtecan languages. Summer Institute of Linguistics Working Papers 11: 1-16.

Jespersen, Otto. 1949. Modern English Grammar on Historical Principles, Part VII: Syntax. London: Allen and Unwin.

Lambrecht, Knud. 1994. Information Structure and Sentence Form. Topic, Focus, and the Mental Representations of Discourse Referents. Cambridge Studies in Linguistics 71. Cambridge: Cambridge University Press.

- 2001. A Framework for the Analysis of Cleft Constructions. Linguistics 39.3: 463-516.

Lee, Felicia A. 1997. Focus and judgment type in San Lucas Quiavini Zapotec. Proceedings to the 23th Annual meeting of the Berkeley Linguistics Society: 234-44.

Lizarraga, Navarro, Glenda Z. 2018. Morfología verbal de persona y número en chichimeco jonaz. $\mathrm{PhD}$ Dissertation. El Colegio de México.

Palancar, Enrique L. 2004. Verbal morphology and prosody in Otomi. International Journal of American Linguistics 70(3): 251 - 78.

- 2018a. Clefts in Otomi: Extended uses of the copular construction. International Journal of American Linguistics 84(1): 93-145.

- 2018b. Subjects and focus in clefts. In Evangelia Adamou, Katharina Haude \& Martine Vanhove (eds.), Information Structure in Lesser-described Languages: Studies in prosody and syntax, pp. 245-264. Amsterdam: John Benjamins.

Patten, Amanda L. 2012. The English it-cleft: A constructional account and a diachronic investigation. [Topics in English Linguistics, 79]. Berlin: DeGruyter Mouton.

Tonhauser, Judith. 2003. F-constructions in Yucatec Maya. Jan Anderssen, Paula Menendez-Benito, and Adam Werle (eds.), The Proceedings of SULA, pp. 203-23. Amherst: GLSA, University of Massachusetts.

Trechsel, Frank R. 1993. Quiche focus constructions. Lingua 91: 33-78.

Verhoeven, Elisabeth, and Stavros Skopeteas. 2015. Licensing focus constructions in Yucatec Maya. International Journal of American Linguistics 81.1: 1-40.

Ward, Michael. 1987. A focus particle in Quioquitani Zapotec. Summer Institute of Linguistics Working Papers 9: 26-32. 